\title{
Using the Internet for Democracy: A Study of South Africa, Kenya and Zambia
}

\author{
Aletta H Janse van Rensburg
}

\begin{abstract}
For the first time since democracy in the classical Greek sense became practically impossible, the Internet's networking possibilities are creating opportunities for all citizens to be active engaging participants in democracy. Open communication channels to government and fellow citizens can now be a reality that allows people at all levels of society to form part of a vibrant public sphere by exchanging ideas, sharing experiences, spreading ideologies and news, and comparing agendas. For African countries dealing with unique and increasingly complicated political and socio-economic issues, the Internet provides a platform from which citizens can now address these issues themselves and, in doing so, contribute to a public sphere that strengthens the democratic fibre of their countries.

This research posits that the Internet has significant potential to stimulate democratic culture through public discourse and citizen participation. The focus of this study is on finding evidencebased information about the current influence of information and communication technology (ICT) usage in South Africa, Kenya and Zambia as representatives of sub-Saharan Africa, and with specific focus on Internet usage through computers and mobile phones. The research also investigates the capacity and opportunity citizens have to successfully integrate ICTs into the accomplishment of self and mutually identified political goals in order to strengthen a broader democratic culture.
\end{abstract}

\section{Introduction}

The Internet as a platform for citizen participation and public discourse has significant potential to improve democracy in sub-Saharan African states. The continent has for years now been synonymous with instability. Since the majority of African states gained independence in the $20^{\text {th }}$ century, they have been characterised by a myriad of problems including political corruption and human rights violations. Political regimes have failed to give adequate attention to elite abuse, ethnic fears of oppression by the majority, and legitimate group demands for political and social 
rights. In many cases, ethnic minorities have as a result been largely excluded from political processes due to a lack of adequate communication channels (Rothchild, 1995, p. 60).

Information and communication technologies (ICTs) can in a broad sense and for the purpose of this study be described as the platforms by means of which people access the Internet. ICTs have in many ways redefined what we understand to be effective citizenry and citizen participation, which are fundamental to a functioning democracy. Almost 2 billion Internet users worldwide with unlimited information at the push of a button now have alternative access points to the political realm through their computers and mobile phones. Likewise, African citizens are slowly but surely, through the use of the Internet, retrieving some of the power over their own lives and possessions that many believe elected leaders have been wasting (Ott \& Rosser, 1999, p. 137). Many continue to believe that the solution to Africa's problems lies in the utilisation of the Internet to stimulate and improve democracy.

In a new form of collective bargaining the Internet makes visible a layer of social process that is more fundamental than organisations and just as fundamental as institutions, namely, the customs by which people that have something in common think together. Collective cognition is greatly facilitated by the community-building mechanisms of the Internet (Jenkins \& Thorburn, 2004, p. 63) as it creates the opportunity for people to form ideologies, spread news, compare agendas, exchange ideas and share experiences (Rothchild, 1995, p. 54).

This study is, therefore, significant in an African context, where until recently many states have lacked a practical medium through which ordinary citizens could participate in and contribute to a culture of democracy in a non-offensive way that does not endorse the conflict that has in many ways become an everyday occurrence for Africans. In many instances, what are in effect single party systems have condemned opposition to the party in power as treason, and political opponents are often presented as "anti-people" or enemies of the nation and are severely punished and repressed (Hameso, 2002, p. 30). The Internet now provides a platform for communication and networking where traditional media have until now been limited. 
Against this background the purpose of this study is, as far as possible, to calculate how the Internet can be applied to promote public discourse and citizen participation as functions of democracy in sub-Saharan African states. Research suggests that communities are empowered when they become able to take control of their knowledge environment and the conventional paradigm of knowledge (Girard \& Siochru, 2003, p. 41). The study takes into consideration obstacles such as the slow uptake of Internet usage in Africa that is, to a great extent, attributable to limited infrastructure. Other issues - such as low Internet usage by governments, schools, health and agricultural institutions as well as low ICT literacy levels, lack of local content and overall low income levels - stand in the way of the Internet being optimally used for democratisation purposes (Mundy \& Sultan, 2001, p. 10). The study looks into how a culture that stimulates motivation to make use of ICTs to improve living standards and personal development can be fostered in these African states despite these obstacles.

\section{Analysis of the Constituencies}

Three countries were identified to be investigated and were chosen specifically so as to obtain information about the broadest possible spectrum of examples in this region where ICT infiltration and usage vary from very low to high, and where the Internet is currently believed to have a very low to a very high impact. South Africa, Kenya and Zambia were chosen as preliminary research found indications that all three countries are introducing significant measures to improve the availability of ICT infrastructure and Internet usage, most notably for development purposes. The three sample countries proved to have different levels of success with this initiative and the reasons for this were investigated as part of the study.

South Africa was the first country investigated. Being Africa's strongest economy, communication access on the continent is, to a large extent, dominated by South Africa. Just over $15 \%$ (and rapidly increasing) of adults in South Africa access the Internet through their computers which makes it the highest ranking country in sub-Saharan Africa in terms of Internet usage according to the latest comprehensive study (Gillwald \& Stork, 2008, p. 26). Internet access through mobile phones in the country is even greater. Evidence of the integration of Internet usage in the political culture in South Africa has shown that there is tremendous potential for other countries in southern Africa to follow suit. At the same time, traditional media 95 
are coming under increasing pressure from the ruling party who are showing signs of wanting to limit press freedom. In the face of this opposition, the Internet could play a vital role in keeping the country's healthy public discourse alive.

At the lower end, Zambia was chosen to represent in the study countries that have very little Internet usage. While Gillwald and Stork (2008, p. 26) found that $43.4 \%$ of Zambians know what the Internet is, only 3.3\% of citizens make use of it. A limited fixed line network has proved to be a major constraint on Internet access in the country. However, thanks to rapid growth in the number of telecentres and Internet cafés, the number of Internet users is estimated to have risen significantly (Munsaka, 2010). Zambia’s government began to develop a national ICT policy in 2001 through a comprehensive consultation process including inputs from academics and civil society organizations. The policy was finalized in 2005 and adopted by the government in 2006 . It establishes a framework for the future direction of ICTs and ICT for development within the country. The report suggests that the main problem with this national policy has been the length of time taken to put it into place, partly because of the absence of a specialist ICT ministry within the government (Munsaka, 2010).

Lastly, Kenya was chosen because of its government's increased and widely praised efforts in the last decade to improve ICT access and skills. In 2006, Kenya's ICT Board launched an extensive programme to bring ICT access to all rural villages. The government also recently announced that a strategy is being put in place to stimulate local content and application development. On the skills development front, the government is also taking dynamic measures: a recent budget promised 300 computers for schools in every Kenyan constituency, one million laptops initially targeting university students, and various skills development programmes on these fronts (Twinomugisha, 2010). The state's commitment to e-government and the relative success experienced with their initiatives was an important consideration as it could provide insight into the opportunities for using the Internet for democratic practices (Kenya ICT Board, 2011, p. 4).

A thorough study was done of the current status of Internet penetration in the three countries and of the potential there is for growth in this sector. Limited ICT access in the sub-Saharan 
countries is, however, only the first obstacle citizens face. The second level of the problem is a lack of motivation and skill to constructively make use of the Internet. The study looked at the capacity and opportunity citizens have to successfully integrate ICTs into the accomplishment of self and mutually identified political goal in order to contribute to a broader culture of democracy.

\section{Theoretical Framework}

In this section, the researcher addresses the theoretical aspects of how Internet usage could be related to the democratisation process in the sample of countries studied.

There are a number of constructs that are proposed in this part of the study such as the close correlation between digital literacy and democratisation in optimising civil liberties in Africa. Another competency is the domestication of the western model of media and democracy to fit the African socio-political and economic fabric. A third aspect is the careful observation of the transitional mechanism of African countries into democratisation as an integral part of imposed democracy after independence. The cornerstone for such development is their cultural expectations and readiness to actualize democratisation.

The theoretical overview offers an analysis of the main issues and theories that frame the use of the Internet for the development of democracy in the sample countries. A theoretical discussion of the ideal or goal, which is democracy, as well as a brief investigation into Africa's challenges in this regard is necessary to clarify what precisely the objective in terms of stimulation or enhancement of democracy is.

\subsection{Democracy and Africa's Challenge}

Jack Balkin writes that the purpose of freedom of speech is to promote a democratic culture. He argues that democratic culture is more than representative institutions and deliberation about public issues. Rather, he writes, "a democratic culture is a culture in which individuals have a fair opportunity to participate in the forms of meaning making that constitute them as individuals. Democratic culture is about individual liberty as well as collective self-governance; it is about each individual's ability to participate in the production and distribution of culture" 97 
(2004, p. 4). A democratic culture is democratic in the sense that everyone, even those outside the political, economic, or cultural elite, has a fair chance to participate in the production of culture, and in the development of the ideas and meanings that constitute them and the communities and sub-communities to which they belong.

After years of colonial oppression, the early 1990's witnessed a dramatic return of multi-party democracy to Africa. However, in 1995 when all African states were categorised as democracies, most of them were theoretically considered to be highly centralised, authoritarian and selfserving. They were also mostly serving political authorities, high-ranking military leaders or elite political groups (Mengisteab \& Daddieh, 1999, p. 60).

Many academics have since warned against adopting a concept like democracy from Western contexts and applying it blindly to Africa. In his essay "Theorizing the Media-Democracy Relationship in Southern Africa," Guy Berger posits that the main aim for advocates of freedom in Africa should be to acquire universally applicable concepts "which are relevant and explanatory for media and democracy in Africa, and which designate broad processes and functions rather than specific institutions like parliaments and the press” (2002, p. 30).

Berger continues that the functioning of democracy must be defined as the decision-making power of the majority, in which all participants have equal rights, emphasising Balkin's functional definition of democratic culture. Berger makes a clear distinction between broad democratic principles and structures and the processes by which people engage in decisionmaking. This allows for democracy to extend into the realm of the "private", such as the family and community, which in turn enables members of the "private" to meaningfully partake in an active democracy. According to Berger, this is particularly important in an African context where the cultural focus rests heavily on community and tradition (Swedish International Development Cooperation Agency, 2009, p. 20).

At the heart of Africa's problem lies a lack of active citizenship and the proper utilisation thereof. Roman Gerodimos identifies access to the decision-making process as citizens' 
engagement with the political process, deliberation and impact on public policy as key aspects of democracy in action (2001, p. 27). This can only be achieved in a system that allows for an active public sphere. Jürgen Habermas (1991, p. 34) famously attempted to define the operations of the so-called "public sphere" in his essay "The Structural Transformation of the Public Sphere." He described the public sphere as a space between the people and the state in which citizens could debate issues of common interest to society. An important criterion of the public sphere was that it provided a shared common arena for all segments and citizens of society, an arena in which issues could be engaged.

\subsection{Communicating Politics}

The changing nature of communication ushered in by the dawn of the age of electronic communications has changed the nature of political interaction profoundly. The advent of ICTs, and especially the Internet and mobile phones, which are platforms for new media, has added a new, global dimension to the operations of modern democracies and has in effect created a new "global public sphere” or a global civil society. The global public sphere does not displace, but supplements national public spheres and governments. It adds the benefit of bringing a larger diversity of agents to the conversation. This inevitably demands greater accountability and good governance from political actors (Marginson, 2008).

While many argue that the actual political decision-making process remains in the hands of ascertained individuals, the complexity of information which those individuals use to engage in this process is increasingly subject to influence by the changing nature of communications. As electronic and digital communication enable citizens to directly and instantaneously convey their wishes to their representatives and to each other, political interaction is bound to be influenced. There is now greater access to the representatives of the individual in the political system, as well as to important information, decisions and pending legislations that might affect the individual (Ott \& Rosser, 1999, p. 130).

\subsection{Empowering the Individual}

As mentioned before, access to the Internet is only one of the prerequisites for the utilisation of new media for democracy. Jan van Dijk argues that motivation is the initial condition of the 99 
process of new media access and appropriation of the technology concerned. Motivation, according to him, explains why subsequent kinds of access are reached or not (Van Dijk, 2005, p. 21). The question beckons then how Africans can be motivated to gain access to information and communication technologies. Necessary resources for this can be divided mainly into three categories. These are (a) material resources, (b) social resources, and (c) cognitive resources.

The first relevant resource is what has already been mentioned, i.e. the material. Material resources refer to the availability of or access to hardware, software, applications, networks and the usability of ICT devices and applications (Fuchs \& Horak, 2008, p. 101). This includes the financial capacity to either own a computer or mobile phone and the ability to cover connection costs, or the ability to access the Internet at a school, university or Internet cafe.

Social resources include social support that can provide assistance in using and managing material resources. Social contacts such as friends, family, colleagues, teachers and acquaintances are the agents who first learn and then advise other users in using technology. Having a large social network consisting of many computer and Internet users is pivotal for a user that is to cross the motivational access barrier. The unconnected are often isolated and therefore have no motivation to start using the Internet (Van Dijk, 2005, p. 37).

Cognitive resources can be divided in two sub-categories. The first constitutes basic knowledge of computers and the Internet and the ability and skills to use them. This aspect of access was long ignored by scholars of the digital divide but is increasingly receiving more attention. A study done by Freese, Rivas and Hargittai in the United States of America found that people with higher general cognitive ability are more likely to have broadband access. They also tend to have adopted the Internet earlier and to use it more often. All of these outcomes seem likely to be associated with the practical ability to use the Internet efficiently and effectively (2006, p. 246).

The second sub-category constitutes individual psychological capacity to use the Internet. Research on ICT acceptance in developing countries indicates that psychological factors shape motivation, perceptions, and attitudes towards technology and usage behaviour, all of which, in 
turn, predict usage intention. Self-determination theory (SDT) is a psychological theory that emphasises the influence of self-motivation on regulating and changing behaviour which, in turn, affects behavioural outcomes (Techatassanasoontorn and Tanvisuth, 2008, p. 4). SDT identifies three essential psychological needs that, when satisfied, will facilitate an individual's positive personal growth and social development. They are a) the need for competence, b) the need for autonomy, and c) the need for relatedness.

In addition to SDT, the term 'self-efficacy' describes an individual's belief in his or her ability to successfully perform a specific activity (Techatassanasoontorn and Tanvisuth, 2008, p. 5). Studies have shown that ICT skill training increases self-efficacy which, in turn, influences ICT acceptance. This suggests that the incorporation of self-efficacy in research will improve an understanding of the flow of behaviours from decisions to receive training to ICT skill development and subsequent acceptance. Computer self-efficacy refers to “an individual's judgement of efficacy across multiple computer domains as well as performing specific computer-related tasks” (such as using the Internet) (Marakas, Johnson and Clay, 2007, pp. 1646).

This brings us back to the question of how a culture that stimulates motivation to make use of ICTs in order to improve living standards and personal development is to be fostered in African states. In the case of young and developing democracies, it is essential for institutions, processes and mechanisms to be in a place to support and underscore national efforts to strengthen democracy. Failure to do so, some argue, is to leave inexperienced democracies to chance and often at the mercy of unchecked abuse by governments.

In addition to raising awareness and building understanding of (i) the potential of ICTs to connect people, (ii) democratic principles and practice, and (iii) the potential of ICTs to advance democracy it is critical that the community voice in public debate and decision-making be strengthened to maintain transparency and accountability by government. It is, therefore, important to establish strong non-government organisations and media practitioners to engage 
critically on issues of democracy as well as institutional strengthening of state actors to enhance transparency and efficient governance (Mundy and Sultan, 2001, p. 11).

\section{Evaluating the Evidence}

The measurement of democracy takes place in various ways and takes into account democratic institutions, administrative processes and political parties as well as encouraging initiatives by different actors in civil society, opinion-forming organisations and human rights defenders. Importantly, conclusions drawn from previous studies on democratisation processes underscore the importance of grass root movements for bringing about social change and democracy. The assimilation of information and communication technologies in development cooperation also has the potential to promote democracy as it allows the masses to engage with one another and with the system. This includes aspects such as the promotion of freedom of speech, the free flow of information and the promotion of human rights, poverty reduction and social equity (Swedish International Development Cooperation Agency, 2009, p. 13).

To gain comprehensive knowledge of the current role of ICT's in the three countries' democracies, three areas were focused on. For the purpose of their specific knowledge of (a) ICTs for development, (b) ICTs for democracy, (c) ICT infrastructure and (d) new media and democracy. Several experts from a pool of researchers, ICT consultants, government departments and private sector companies were interviewed to extract, without a field study, the most accurate firsthand information on the topic. The interviewees all either have experience in the ICT sector or have studied the topic extensively. Each interviewee was interviewed on only one of the three countries.

Research questions were shaped around the Integrated Self-Determination and Self-Efficacy Theories of ICT Training and Use by Techatassanasoontorn and Tanvisuth (2008, p. 4).

The main focus of the interview questions was threefold: 102 
1. What factors are currently shaping Internet usage?

2. What is currently being done to promote Internet usage?

3. What more can be done to promote Internet usage for the strengthening of democracy?

\subsection{The Technical Assessment}

Zambian interviewees were in consensus that the recent liberalisation of the Zambian communications market and Internet sub-sector that saw the opening up of the so-called "international gateway" is at present the most defining trait of the ICT sector in the country. This has provided stakeholders with the opportunity for vast investment into the sector to join MTN, Vodacom and Airtel as the main stakeholders in the market. Zambia's large youth population constitutes a lucrative mobile market, and it is estimated that every household in Zambia owns at least one mobile phone and this statistic is constantly increasing in urban areas (Musosha, personal communication, December 8, 2010). However, specifically mobile service providers have been limited to three for the next five years after the government estimated that the current levels of market demand for mobile service could not sustain more competition (Lwao, personal communication, December 5, 2010). While the full utilisation of mobile phones is still under scrutiny, interviewees agreed that the governing party have embraced the technology and they believe that the trend can only be upwards.

Internet Service Providers have also started forming alliances that have seen more areas of Zambia being connected. In 2009, the government reduced taxes on telecommunication equipment which stimulated access. The state-owned telecommunications company, Zamtel, was privatised giving the market access to technology that had previously been privy to government. The new LAP Green Networks, a Libyan telecommunications company, has invested over \$1 billion in fibre-optic technology. This will see about $80 \%$ of Zambia having Internet access via fibre (Musosha, personal communication, December 8, 2010). 
In comparison, Kenya's liberalization process that began in 1999 encouraged competition and moved Internet services from a state controlled-monopoly to the private sector. The private sector immediately identified ICT as a critical economic growth sector and started investing in various infrastructure projects especially in the mobile sector that ended up lowering entry barriers. Efficient policies and good costing of products have been major contributing factors to growing Internet usage in Kenya. The private sector together with civil society played an important role in pushing for correct ICT policies. This ensured a sector where there is not only sufficient infrastructure and policies, but also a strong private sector to provide services to customers. The cost of Internet was reduced significantly and young people increasingly started more cyber cafes. Today, Kenya has almost 20 million mobile subscribers and the youth use mobile phones for Internet access. Kenya managed to create a very balanced environment from which users and providers could benefit (Muiruri, personal communication, December 2, 2010).

At present, $85 \%$ of the population have access to a mobile signal. Geographically, however, the signal reaches about $35 \%$ of the population. With the north of the country being scarcely populated, it is not always profitable for mobile operators to roll out infrastructure, and it is not economically viable for the mobile operators to cover certain areas (Waweru, personal communication, November 10, 2010).

In South Africa, the situation is somewhat different. Over $90 \%$ of the population is covered by a mobile signal, but only 15\% of citizens make use of the Internet. While in Zambia and Kenya the situation is exacerbated by the geographical layout and spread of the population, in South Africa it is the product of deep class divisions in society and the financial inability of citizens to participate in Internet usage. While growth in mobile access has greatly increased voice access, there has been little policy intervention through the creation of more competitive markets, or effective regulation of pricing, to address usage issues. Pricing remains a major barrier to access and usage of both fixed-line and mobile phone services. In addition, the cost of equipment such as Internet-enabled mobile phones and personal computers is prohibitively high as is the cost of accessing services, which has limited the uptake of data services (Levin, personal communication, December 1, 2010). Recently installed policies to bring down prices to support 
consumers took effect in 2010 with limited results. Telkom remains the only fixed line Internet service provider, monopolising the market.

However, the $15 \%$ of South Africans who do use the Internet are mostly active users. The youth are accessing the Internet increasingly through mobile phones for social interaction. New services are making their way to citizens through the Internet, i.e. government services, ID application tracking, and many others such as applications to check matriculation results for education and learning, and even personalized health information services. More and more services either by government or private sector are now accessed by cell phones. This is becoming a trend, for example, in the reservation of bus tickets and checking for flights online (Mosieu, personal communication, January 4, 2011).

With the aforementioned factors shaping each country's ICT sector and Internet usage, it becomes imperative to ask how the Internet can be brought to people at the grass roots in each country in order to create an active public sphere. Only by reaching the grass roots of communities, will the digital divide in Africa further be crossed as the Internet has become "a requisite for overcoming inequality in a society which dominant functions and social groups are increasingly organized around the Internet” (Castells, 2000, p. 248).

As hypothesised in the theoretical framework of this study, the challenge for democracy in these African countries lies in increasing all citizens' capacity to use the public space to engage in and influence their governments' decision-making and democratic practice. When compared to developed countries, all three sample countries are unable to provide their citizens with this mainly due to a lack of ICT infrastructure and the high cost of accessing the Internet. In Zambia, there remains a big gap between the investments being made in the ICT sector and the benefits reaching the people. Despite the relative success of Universal Access initiatives setting up telecentres in rural areas, the visibly high cost of last-mile solutions that Internet Service Providers still charge people prevent better usage (Lwao, personal communication, December 5, 2010). Access to affordable hardware is still beyond the reach of many. The lack of critical masses 
subscribing to Internet services leaves Zambia one of the most expensive countries for accessing the Internet (Musosha, personal communication, December 8, 2010).

In Kenya, Internet cafes can be found in very remote rural places, but the cost of Internet similarly remains high. With the subterranean fibre-optic cables reaching Kenya, the situation should, however, change. Research institutions focused on Kenya have emphasised an urgent need to put policies in place to allow rural areas to participate in the digitization of government records as a strategy of attracting the private sector's attention to the rural areas. Outsourcing strategies are further being discussed for potential sustainable ICT growth in rural areas (Muiruri, personal communication, December 2, 2010). Government projects to encourage Internet usage are Pasha and the Digital Villages projects wherein government is building computer centres in rural villages with the hope that from there Internet usage will spread. A bigger demand for Internet connection in these areas will also attract banks and the mobile service providers (Waweru, personal communication, November 10, 2010).

South Africa, while to a certain extent offering better services to consumers, continues to have only 15-20\% Internet usage. This goes hand in hand with a 30\% unemployment figure (Akoojee, personal communication, December 14, 2010).

\subsection{ICT's for Democracy}

The Zambian case for ICTs for democracy is an interesting one. Specialist interviewees all agreed that while the Internet can be a powerful tool in the development and strengthening of a country's democracy in general, there is little potential for the Internet to stimulate democracy in Zambia. One argument was that most leaders have little appreciation of the value the Internet can bring in socially uplifting the Zambian people, hence the sluggish approach to addressing ICT issues. To many, the Internet remains a mysterious tool. Another opinion was that democracy may not necessarily be strengthened due to increased Internet access in any way in the near future because of the extremely low level of Internet access at present (Lwao, personal communication, December 5, 2010). Furthermore, computer literacy and use within the public sector is not very robust and the inclination to make use of the Internet simply does not exist. An 
awareness of the important role the Internet can play in the democratic context of Zambia does exist among the researchers interviewed. The perception that the government does not grasp the importance of the Internet for democracy does not extend to their understanding of ICTs for development, as it can clearly be seen that the government is investing a lot of resources in development and education projects.

Contrastingly, Kenyan specialist interviewees were positive that the Internet already plays a significant role in the democracy of the country. Two interviewees referred to the role of the Internet during elections in Kenya. A Kenyan website named Ushahidi.com was used in 2007 to communicate and relay information during the tumultuous national elections. The site functions as a social network and spreads information nationally and internationally about the violence that erupted during the elections, connecting people and allowing them full access to information concerning the political climate in the country at the time. The website still functions as a popular social network in Kenya (Waweru, personal communication, November 10, 2010).

Another interviewee pointed out that it is very hard to manipulate a citizen who has the ability to check information. During election periods, politicians across the board manipulate the citizens who have no access to information. Unfortunately most of them are fed and believe half truths that cannot be verified. Most of these citizens are young and unemployed either in urban slums or rural areas that are not well served with infrastructure to facilitate Internet access. They are the most disadvantaged and vulnerable and are usually drawn in conflicts that empower politicians to ascend to high offices. Providing Internet access in the slums and rural areas and identifying champions in these target populations will play a big role in promoting democracy as the Kenyan youth can verify any claims by politicians by visiting blogs or merely reading different opinions from fellow citizens (Muiruri, personal communication, December 2, 2010).

In Kenya, The Internet was started by the people returning from the West where they had to utilise the Internet for their studies. Additional research indicated that those working with international organizations were more likely to use the Internet through work exposure than those who were working with local organizations. Most international organizations are found in 
Nairobi and other urban areas, so it goes without saying that those in rural areas have been at a disadvantage based on limited exposure. Some cultural norms also suggest that the Internet has corrupted the youth through exposure to wrong cultures, and there is some hesitance to utilise the tool. This is, however, slowly disappearing as more and more students receive exposure in schools.

Reactions from South African interviewees were mixed. Pessimism about the Internet's role in democracy was founded on the fact that penetration and access, if not usage, is already high without it contributing to democracy. A lack of government initiatives and motivation were also cited as reasons for the lack of potential. Even though the Internet is widely available in the country, there is not enough initiative from the government, firstly, for the infrastructure to reach the masses of poor South African citizens and, secondly, for the citizens to acquire the necessary skills and training to use the Internet efficiently (Akoojee, personal communication, December 14, 2010). Additionally, emphasis was placed on socio-cultural norms and practices as tremendous barriers to Internet usage. Learners' and students' lack of inclination towards mathematics, science subjects and traditional cultural practices lead them away from using technology, a problem specific to South Africa (Levin, personal communication, December 1, 2010).

However, in contrast to the above, others do believe that there is tremendous potential for the Internet to strengthen and improve democracy in South Africa, specifically because of the country's higher access. Government and political parties have made extensive use of the Internet for political campaigns, ministerial websites, and the distribution of information and general e-governance practices. A strong and deliberate effort to bring the Internet to all citizens can only be driven by the government. The country's robust and independent news media sector furthermore contributes to efficient and transparent governance. Citizen journalism through blogs and social networks facilitate conversation and contribute to a healthy public sphere in South Africa.

\section{Conclusion}


The purpose of this study was to investigate the potential and identify the possibilities for the Internet to be utilised in improving democracy in sub-Saharan African countries. The study contains a theoretical discussion of all relevant areas concerning ICT infrastructure, ICTs and democracy and ICTs and development, with special investigation into ICTs in education. In addition, the study includes a description and analysis of the limitations, challenges and possibilities for promoting democracy through the Internet in South Africa, Kenya and Zambia.

The theoretical overview highlights the importance of public debate and deliberation on political choices in a feasible public sphere for the full achievement of a democratic culture. It is of particular significance to create the capacity for public deliberation among a cross-section of civil society actors in order to cultivate an open conversational space in which social groups with diverse interests are able to hold government accountable. A culture of transparency should be cultivated in contrast to being threatened by critical debate. Central to creating a culture of accountability and transparency is the availability of public information. The task of providing this falls to the respective governments.

From the technical assessment several findings were drawn. While access to infrastructure remains a significant challenge, existing infrastructure is substantial enough to render the Internet a powerful facilitator and tool to promote democracy. With access to mobile phones high access to the Internet will increase accordingly in all three countries. Several fibre-optic cables are underway or already in use in countries across Africa. These should provide widely available broadband access within the next two years. This should lead to connection costs coming down.

South Africa's liberal constitution assures the conservation of its democracy, although severe poverty deprives a large part of the population of certain political and human rights. Several civil society organisations are focused on ICTs for democracy, promoting the use of the Internet for better access to information, more accessible channels of communications to government and general public conversation. However, the level of awareness about the importance and potential 
of the Internet to strengthen democracy is very low, equally so in government as amongst citizens.

After two decades of political instability, Kenya is slowly heading towards a consolidated democracy. The role ICTs are playing in this process is negligible. Importantly, however, the Kenyan government has recently given priority to ICTs for the promotion of democracy in recognition of the important role it can play. Several projects have been launched in support of government objectives to enable all citizens to be part of a political and public sphere. As in South Africa, ICTs for democracy in Kenya have been poorly researched. This is partly due to unawareness about the importance of the topic, as well as the relative novelty of the field of study.

In Zambia, the situation is more complicated. Internet usage in Zambia remains extremely low despite access being available. This creates an impediment for the use thereof for democratic purposes. Consequently, no civil society organisations exist that are focused on ICTs for democracy. Research about the topic focused specifically on Zambia is also minimal. While government have launched some projects, a lack of awareness about the potential of the Internet hinders efforts to bring the Internet to more citizens.

In all three countries, there has recently been a definite shift toward the accommodation of information and communication technology. This includes the liberalisation of markets as well as government initiatives to bring access to all citizens. Mobile phones are the leading medium for accessing the Internet. However, importantly, mobile phone usage should not be regarded as similar to Internet access through mobile phones as many citizens do not use their mobile phones to connect to the Internet. It is therefore important not to overestimate the number of people accessing the Internet through their mobile phones.

Efficient policies and good costing of products can be major contributing factors to growing Internet usage. Such an impact could be seen in Kenya. The geographical layout of all three countries furthermore influences Internet usage. Rural areas are less likely to be covered by an 
Internet signal than urban countries. Incentives in the private sector to cover these areas are low as estimated profits are marginal.

Lack of funding in the public education system in all three countries inhibits the use of ICTs in public schools. Teachers' lack of skills exacerbates the problem. In addition, not nearly enough children in public schools have access to the material or social resources to be active, purposeful users of the Internet. However, the area governments have been most active in has been in developing schools' ability to supply learners with access and skills, and the number of projects aimed at ICTs in education is growing constantly. Most tertiary education institutions in Zambia, and all in Kenya and South Africa, have access to the Internet.

Experts furthermore agreed that there is clearly a role for the Internet to play in assisting in the consolidation and growth of these democracies, even though Zambian experts were pessimistic about this. Significant social change such as greater use of the Internet for the stimulation of democracy can only be driven from the grass roots level, and successful campaigns were driven during the 2007 Kenyan elections.

The use of the Internet for personal, micro-economic affairs has increased over the last five years, and this has contributed greatly to the development of all three nations. Very little of this activity has been specifically political but, as argued earlier, democracy cannot be successful without continuous national development.

The great majority of ICT applications in Africa are imported and are developed in developed countries. It is imperative that this technology is adapted to indigenous knowledge and local cultures if all citizens are to benefit from using the Internet. Past projects have shown people in Kenya and South African react positively to applications catering to their specific needs.

Millions of Kenyans expressed their opinions about the government and political process during the 2007 national elections on the social network website Ushahidi.com. This mass participation in the public debate put tremendous pressure on state officials not only by bringing international 
attention to the elections, but by demanding accommodation by the state. In South Africa, election campaigns on the Internet are becoming increasingly prevalent, although support rallied in this way has been only marginally influential.

\section{Recommendations}

After careful consideration of the theoretical starting point and findings as well as the findings from the interviews conducted with specialists in the field and the technical assessment, several recommendations can be made for the utilisation of the Internet to stimulate and strengthen democracy in South Africa, Kenya and Zambia.

Firstly, it is imperative that awareness is raised about the important possibility for the Internet to improve democracy. This campaign should be driven by government and state officials as well as by citizens. Both groups need a particular understanding and appreciation of the opportunities presented by the Internet not excluding the potential there is for social and economic uplifting in the developing contexts of the countries. Importantly, concepts and practices such as government accountability and transparency, public debate and participatory democracy need to be embedded in the foundations of citizens' upbringing. A thorough understanding of this goal needs to be present before any progress will be made towards it. Democratic values, norms and practices need to be instilled by the education system. This can also be achieved through Internetfacilitated civic education projects.

Secondly, the capacity and leadership of institutions responsible for advancing democracy should be strengthened. How this can be done constitutes an entirely separate study. What can be said, however, is that political capacity for providing efficient policies and oversight to promote good governance is essential. Emphasis should be placed on including all people, especially at grass roots level. Additionally, an enabling policy and regulatory framework should be put in place. Such policies already exist in all three countries, but Zambia could benefit from future reforms for better efficiency. Policies that allow affordable access to the Internet through both mobile phones and computers will lead to citizens being better equipped to hold government accountable and to participate in democratic practices. A reduction in connection costs is crucial to increased Internet usage and, with the arrival of the fibre-optic cables, this is a feasible 112 
possibility. Freedom of expression and information should furthermore be guaranteed, although this is already a prerequisite for democracy and is not merely for the effective use of the Internet.

The researcher would further recommend that ICTs be integrated in the national education system and the funds be made available to do so as it is a top priority. Citizens need to acquire the necessary skills to use the Internet at a young age while simultaneously learning that using the Internet for democratic purposes can contribute to their lives in a positive manner. All three sample countries already have several e-education projects running, but the current purpose of these projects remains the reaching of development goals. It should be possible to incorporate initiatives to promote the use of the Internet for democracy alongside or within these projects.

Access to information and the development of local content is essential to promoting the Internet for democracy in the three African countries. In South Africa, access to information is currently under discussion as the legislature is in the process of shaping a new Protection of Information Bill. It is, however, the conclusion of the researcher that public access to government and state information is crucial in ensuring accountable and transparent representation. The development of local content is furthermore of the utmost importance in enticing citizens to make use of the Internet. After the issue of cultural barriers was raised in several interviews, the researcher came to the conclusion that even though there is no statistic supporting this claim, Internet users can only benefit from digital content developed specifically to cater to their specific needs. This may require deviating from the generic Western models of presenting digital content and promoting Internet projects.

Finally, the fact remains that African countries continue to be unique in their interpretation of democratic principles. In addition, being citizens of developing countries, South Africans, Kenyans and Zambians have unique social, political, economic and cultural needs that naturally differ from citizens in developed nations. Promoting the Internet for democracy in these African contexts should be approached with this in mind. This includes all initiatives in e-government, providing access to information, creating public e-debates and citizen participation through existing media. 


\section{References}

Balkin, J. 2004. Digital speech and democratic culture: A theory of freedom of expression for the information society. New York University Law Review, 79(1): 1-55.

Berger, G. 2002. Theorizing the media-democracy relationship in Southern Africa. Gazette: The International Journal of Communication Studies, 64 (21): 21-45.

Castells, M. 2000. The rise of the network society. The information age: Economy, society and culture (2nd ed.). Oxford: Blackwell.

Castells, M. 2005. Global governance and global politics. Political Science \& Politics. [Online]. Retrieved 4 July 2010 from http://www.apsanet.org/imgtest/2005Global-Castellas.pdf

Chazan, N. 1990. Africa’s democratic challenge: Strengthening civil society and the state. World Policy Journal, 9(2): 279-307.

Cowling, L. \& Hamilton, C. 2008. Thinking aloud/allowed: Pursuing the public interest in radio debate. Social Dynamics, 36 (1): 85-98.

Esselaar, S. \& Stork, C. 2005. Mobile cellular telephone: Fixed-line substitution in sub-saharan Africa. The South African Journal of Information and Communication, 6.

Farrell, G. \& Isaacs, S. 2007. Survey of ICT and education in Africa: A summary report based on 53 country surveys. Washington DC: InfoDev/World Bank. [online]. Retrieved 14 June 2010 from http://www.infodev.org/en/Publication.353.html

Freedom House. 2009. Freedom on the net: A global assessment of Internet and digital media. Washington DC. [online]. Retrieved 7 September 2010 from http://www.greedomhouse.org/uploads/specialreports

Freedom House. 2010. Freedom in the world 2010 survey release. [online]. Retrieved 21 June 2010 from http://www.freedomhouse.org

Freese, J., Rivas, S., \& Hargittai, E. 2006. Cognitive ability and Internet use among older adults. Poetics, 34: 236-249.

Fuchs, C., \& Horak, E. 2008. Africa and the digital divide. Telematics and Informatics, 25: 99116.

Gerodimos, R. 2001. Democracy and the Internet, engagement and deliberation. Journal of Systemic, Cybernetics and Informatics, 3(6): 26-31. 
Gillwald, A., \& Stork, C. 2008. ICT access and usage in Africa. Toward Evidence-based ICT Policy

and Regulation, 1(2): ii.

Girard, B. \& Siochru, S. O. (Eds). 2003. Communicating in the information society. Geneva: The United Nations Research Institute for Social Development for the World Summit on the Information Society.

Habermas, J. 1991. The structural transformation of the public sphere. (T. Burger, Trans.). Massachusetts: MIT Press.

Hameso, S. 2002. Issues and dilemmas of multi-party democracy in Africa. West Africa Review, $3(2)$.

Jenkins, H., \& Thorburn, D. (Eds). 2004. Growing a democratic culture: John Commons on the wiring of civil society. Democracy and new media. Massachusetts: MIT Press.

Kenya ICT Board. 2011. Kenya ICT board monitoring and evaluation survey results.

Marakas, G., Johnson, R., \& Clay, P. 2007. The evolving nature of the computer self-efficacy construct: An empirical investigation of measurement construction, validity, reliability and stability over time. Journal of the Association for Information Systems, 8(1): 16-46.

Marginson, S. 2008. The universal value and the development trend of civilization. In The knowledge economy and the global public sphere. Presented at the Beijing Forum 2008.

Mengisteab, K. \& Daddieh, C. 1999. State building and democratisation in Africa. Faith, hope and realities. The Journal of Modern African Studies, 33(1): 53-65.

Mundy, P. \& Sultan, J. 2001. Information revolutions: How information and communications management is changing the lives of rural people. Wageningen, The Netherlands: CTA.

Munsaka, J.S. 2010. Report published as part of the Regional ICT Discussion Forum Project, coordinated by SANGONeT. [online]. Retrieved 5 November 2010 from www.ngopulse.org/files/Zambia_Research_Report.pdf.

Ott, D., \& Rosser, M. 1999. The electronic republic? The role of the Internet in promoting democracy in Africa. Democratization, 7(1): 137-157.

Rothchild, D. 1995. Ethnic bargain and state breakdown in Africa. Nationalism and ethnic Politics, 1(1): 54-74.

Swedish International Development Cooperation Agency. 2009. ICT's for democracy: Information and communication technologies for the enhancement of democracy with a 
focus on empowerment. [online]. Retrieved 15 June 2010 from Sida:

http://www.Sida.se/publications.

Techatassanasoontorn, A. \& Tanvisuth, A. 13 December 2008. The integrated selfdetermination and self-efficacy theories of ICT. Training and use: The case of the socioeconomically disadvantaged. Paris: SIG on Global Development Workshop.

Twinomagishu, A. 2010. Government ICT seriousness rankings: Kenya most serious about ICT. [online]. Retrieved 6 July 2010 from http://www.ictworks.org.

Van Dijk, J. 2005. The deepening divide: Inequality in the information society. California: Sage. Van Dijk, J. 2006. The network society.(2 ${ }^{\text {nd }}$ ed.). Chippenham: Sage.

Wanjiku, R. 2009. Kenya Communications amendment act 2009. Progressive or retrogressive? A part of the Association for Progression Communication's Communication for influence in Central, East and West Africa (CICEWA) project. [online]. Retrieved 20 July 2010 from http://www.apc.org/en/system/files/CICEWAKenya20090908_EN.pdf. 


\section{Name}

Aletta H. Janse van Rensburg

\section{Qualification}

MA in Political Communication, University of Cape Town 2011

\section{Biography}

Alet Janse van Rensburg is a PhD student in Political Communication, Centre for Film and Media Studies and Journalist for Media24, University of Cape Town. Her field of focused study is the politics of climate communication. She also works full time as a news reporter for a daily newspaper.

\section{Contact}

Email: aletjvr@gmail.com

Phone: 0782235759 